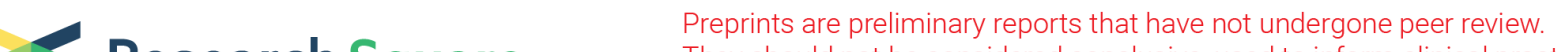 Research Square
or referenced by the media as validated information.
}

\section{Mechanism of The Summer Rainfall Variation in Transitional Climate Zone in East Asia From the Perspective of Moisture Supply During 1979-2010 Based On The Lagrangian Method}

\section{Qiulin Wang ( $\nabla$ wangql@lasg.iap.ac.cn )}

Institute of Atmospheric Physics Chinese Academy of Sciences https://orcid.org/0000-0001-91134546

\section{Gang Huang}

Institute of Atmospheric Physics Chinese Academy of Sciences https://orcid.org/0000-0002-86927856

\section{Lin Wang}

Institute of Atmospheric Physics Chinese Academy of Sciences https://orcid.org/0000-0002-38104724

\section{Jinling Piao}

Institute of Atmospheric Physics Chinese Academy of Sciences

\section{Tianjiao Ma}

Institute of Atmospheric Physics Chinese Academy of Sciences

\section{Peng Hu}

Institute of Atmospheric Physics Chinese Academy of Sciences

\section{Chakrit Chotamonsak}

Chiang Mai University

Atsamon Limsakul

Environmental Research and Training Center

\section{Research Article}

Keywords: Moisture sources, Summer precipitation, Transitional Climate Zone, Lagrange method

Posted Date: November 24th, 2021

DOI: https://doi.org/10.21203/rs.3.rs-1069723/v1

License: (c) (1) This work is licensed under a Creative Commons Attribution 4.0 International License. Read Full License 


\section{Abstract}

Transitional Climate Zone (TCZ) over East Asia, characterized by semi-arid climate, is ecologically fragile environment with limited water resources, making atmospheric moisture supply being the key influential factor. This study investigates the moisture sources of summer (JJA) rainfall in the TCZ over East Asia during 1979-2010 with the Lagrangian particle dispersion model. Seven moisture source regions and associated contribution are quantified: Eurasia continent to northwest of the TCZ (EC, 18.01\%), centraleastern China (CEC, 17.14\%), western Pacific Ocean (WPO, 7.46\%), South China Sea and Indonesia (SCSI, $3.56 \%$ ), Bay of Bengal (BOB, 2.55\%), Arabian Sea (AS, 2.13\%) and local evaporation (TCZ, 19.96\%). The moisture contribution from ocean $(16.06 \%)$ is less than those from the continent $(55.11 \%)$, due to the great loss en-route. In particular, the local evaporation not only contributes the most moisture among 7 selected source regions, but also has the greatest influence in summer precipitation variability in TCZ. Furthermore, westerlies precipitation and monsoon precipitation are discriminated according to the dominant system of water vapor source regions. It is found that summer monsoon contributes most of water vapor (33.2\%) to summer rainfall in TCZ, while only $18.01 \%$ comes from the mid-latitude westerlies dominant area. Finally, further analysis of dry and wet years shows that summer monsoon system also takes more responsibility for a drier or wetter summer in TCZ from the perspective of moisture supply, followed by local evaporation and mid-latitude westerlies.

\section{Introduction}

The Transitional Climate Zone (TCZ) over East Asia, also known as the monsoon transitional zone between monsoon and non-monsoon regions, stretches from the eastern fringe of the Tibetan Plateau to Northeast China. Due to the influence of the interannual variability of the monsoon and the mid-latitude westerly winds, this area is featured by large gradients of climate and biome. It is also the farmingpastoral ecotone (FPE), whose response of vegetation growth to climate change, especially to precipitation variation, is relatively sensitive in TCZ (Ou and Qian 2006, Lu and Jia 2013). In addition, TCZ is featured by semi-arid climate and highly vulnerable to climate change. With the pace of global warming, extreme weather events will become more probable(Wang and Chen 2014) in China. In particular, the TCZ has experienced the largest warming over East Asia and the most significant aridification in the last century (Li, Huang et al. 2015, Huang, Li et al. 2017, Huang, Ma et al. 2019). A new global desertification vulnerability index constructed by Huang, Zhang et al. (2020) in which both climate change and human activity are considered, suggested that this area have a high risk of desertification. There have been studies about the dry-wet conditions of TCZ. Wang, Chen et al. (2017) suggested the precipitation variation is the main fact affecting inter-annual fluctuation of both fringes of TCZ while increasing evaporation plays an important role in the long-term trend. Our previous study also investigated the temporal and spatial variation of TCZ in summer during 1961-2018, finding that the dry and wet conditions of the transition zone vary greatly from year to year, which are mainly caused by summer precipitation(Wang, Wang et al. 2020). Therefore, it is necessary to explore the mechanism of precipitation change in TCZ. 
Sufficient water vapor supply is one of the necessary conditions for precipitation formation.

Characterized by semi-arid climate, limited water supply makes it necessary to explore moisture source of TCZ. Eulerian method is a common method to analyze water vapor transportation and the budget of water vapor in an atmospheric column with grid data (Trenberth and Guillemot 1995, Simmonds, Bi et al. 1999, Oshima, Tachibana et al. 2015, Zhu, Wu et al. 2020). However, it provides simple moisture transport paths and fails to show detailed information on the geographical sources of the moisture since the meteorological field is transient (Sodemann, Schwierz et al. 2008, Drumond, Nieto et al. 2011). On the contrary, lagrangian analog can make up these defects by facilitating better source-sink relationship since it allows researchers to trace along the air block trajectory and shows changes of spatial position and moisture content (Zhihong, Wei et al. 2013, Salih, Zhang et al. 2015, Peng, Zhou et al. 2020, Wang, Li et al. 2020).

Lagrangian particle dispersion models (LPDMs) are proved versatile tools for simulating the transport and turbulent mixing of gases and aerosols in the atmosphere, and have been widely used in hydrologic cycle research, such as the Hybrid Single-Particle Lagrangian Integrated Trajectory (HYSPLIT) model (Hao, Zhihong et al. 2014, Cohen, Stunder et al. 2015, Wang, Li et al. 2020) and the FLEXible PARTicle (FLEXPART) model (Pisso, Sollum et al. 2019). FLEXPART model has been widely used in addressing moisture transport. Peng, Zhou et al. (2020) explored moisture sources of central Asia which is associated with the deep low trough over central Asia and the anticyclone over North Africa and western Asia in the lower and middle troposphere. Nieto, Gimeno et al. (2006) examined the main sources over the Sahel, suggesting recycling was the dominant moisture source over the Sahel. Salih, Zhang et al. (2015) identified source regions of water vapor for Sahelian Sudan during the monsoon period with FLEXPART. In their latter study(Salih, Zhang et al. 2016), they compared it with results comes from atmospheric general circulation model with an embedded moisture-tracing module (Community Atmosphere Model version 3), finding that two approaches differ when comparing individual regions, but are in better agreement when neighboring regions of similar atmospheric flow features are grouped together. They suggested that longer back trajectories in FLEXPART would have been necessary to capture a more realistic transport, although it also implies larger errors.

Large efforts from the scientific community have been devoted toward a better understanding climate change during summer in East Asia, especially the adjustment of summer monsoon system and middle and high latitude systems(Qian, Wu et al. 2010, Huang, Liu et al. 2011, Huang, Liu et al. 2012, Wang, Zuo et al. 2017, Chen, Wang et al. 2019, He and Zhou 2020). However, TCZ is a interaction region of warm and wet air mass controlled by monsoon and dry and cold air mass in the westerlies(Huang, Li et al. 2017, Wang, Chen et al. 2017). Wang, Wang et al. (2020) suggests the interannual variation of summer wet-dry condition in TCZ is mainly influenced by EASM circulation and the low-pressure anomaly over Mongolian area. In addition, the teleconnection pattern over Eurasia excited by warming sea surface temperature in the North Atlantic is concerned with the interdecadal change of summer rainfall in TCZ in the 1990s (Piao, Chen et al. 2017, Zhao, Chen et al. 2020). However, it is difficult to quantify the effect of different systems on the wet-dry conditions of TCZ. Lagrange diagnose provide a new thinking. Here, we applied the latest version of FLEXPART (FLEXPART_10.4v) to trace back the trajectory of the air mass over TCZ 
during summer (JJA) from 1979 to 2010, identify main source regions and quantify their contributions to the summer rainfall of TCZ.

This paper is organized as follows. Section 2 describes the model, input data, and methods to identify source regions and contribution quantification. Section 3 demonstrates model results including the air particle trajectories and identification of major moisture source regions, along with quantification of moisture contributions from main source regions and how they behave in wet/dry year. The role of monsoon system and mid-high latitude systems in summer precipitation in TCZ will also be discussed in this section. A conclusion is provided in Section 4.

\section{Data And Method}

\subsection{Data}

The model is driven by the National Centers for Environmental Prediction-Climate Forecast System Reanalysis (NCEP-CFSR) 6-hourly forecast data (Saha, Moorthi et al. 2010)from 1979-2010, including land cover, temperature, relative humidity, and three-dimensional winds at 42 levels with a horizontal resolution of $0.5^{\circ} \times 0.5^{\circ}$. Furthermore, the model simulation quality of summer precipitation in TCZ is verified with observation and reanalyzed datasets. The observation daily precipitation from 1979 to 2010 is retrieved from the National Meteorological Information Center, with a spatial resolution of $0.5^{\circ} \times 0.5^{\circ}$ (Xu, Zhao et al. 2019). And daily reanalyzed precipitation used here is from the Japanese 55-year Reanalysis (JRA-55), the second global reanalysis constructed by the Japan Meteorological Agency (Kobayashi, Ota et al. 2015, Harada, Kamahori et al. 2016), with a resolution of $1.25^{\circ} \times 1.25^{\circ}$.

\subsection{Model simulation and target region}

TCZ is the junction of arid and humid regions, with large spatial gradient of precipitation. In our previous study, TCZ boundary was defined by summer Arid Index(SM_Al) to better investigate the wet/dry condition of TCZ in summer, which is equal to total summer precipitation (MJJAS) divided by total summer potential evaporation during 1979-2010 (Wang, Wang et al. 2020). Due to the complexity of TCZ boundary, a simplified parallelogram is used here as the boundary of the target region (Fig. 1). Since the summer rainy season in TCZ begins in early June and ends in late August (Wang, Wang et al. 2020), we explored the moisture sources of precipitation in TCZ from June to August during 1979-2010. Fig. 1 shows climatology of water vapor flux and its divergence in summer (JJA) from 1979 to 2010. According to the Eulerian water vapor budget equation, the net water vapor flux in this area is negative, meaning that summer precipitation $(P)$ is greater than evaporation(E). The Indian Peninsula, the southern foothills of the Himalayas, the Indo-China Peninsula and tropical western Pacific are the areas of strong water vapor flux convergence, leading to abundant summer precipitation. The western part of Eurasia is subject to moisture divergence, with positive net water vapor flux and greater evaporation than precipitation. TCZ is dominated by eastward water vapor transport with complicated water vapor flux divergence in summer. According to the water vapor transport field, the mid-latitude westerlies dominate moisture transport over TCZ. There are three possible moisture resources during summer in TCZ. Water vapor transported by 
southwesterly bring moisture from the Arabian Sea and the Bay of Bengal as well. Furthermore, the anticyclone along the west margin of the western Pacific high fetches warm and moist air from the tropical Pacific Ocean and South China Sea.

In this study, we explored summer precipitation from June to August. For tracing the moisture transport of the whole period, FLEXPART_10.4v run forward in time every summer (from May 21 to August 31) of 1979-2010 using the domain-filling mode, with 1000000 particles released globally. The model output includes three-dimensional position (latitude, longitude, and altitude), temperature, specific humidity, air density, and mass of each particle, recorded at 6-h intervals.

\subsection{Methods}

In order to find out the water vapor source and sink area, it's essential to get a better idea of the water vapor budget of the air parcels before they reach the target area. The Lagrangian analog(Stohl and James 2004) is applied to diagnose surface freshwater budget, which equals to evaporation(E) minus precipitation $(P)$. For a particle, the net rate of change of the water vapor content is

$$
e-p=m \frac{\mathrm{d} q}{\mathrm{~d} t}(1)
$$

where $e$ and $p$ are the rates of moisture uptake and release along the trajectory, respectively. $q$ is the specific humidity, and dq/dt is the change of specific humidity with time.

The surface freshwater flux in an area A becomes the moisture changes of all particles in the atmospheric column over $\mathrm{A}$

$$
E-P=\frac{\sum_{k=1}^{k=K}(e-p)}{A}=\frac{\sum_{k=1}^{k=K} m \frac{d q}{d t}}{A}(2)
$$

Where $\mathrm{K}$ is the total number of particles in the atmospheric column over $\mathrm{A}$.

The method can also track (E-P) from a region backward in time along the trajectories, finding sources of moisture and precipitation. It is important to notice that the Lagrangian approach is not able to separate E and P. Giving that when rain falls, it normally clearly exceeds evaporation, Stohl and James (2004) suggested that we can assume that $e$ and $p$ cannot coexist in the same location at the same time. That means there is only uptake of moisture $(e>0, p=0)$ happening when $d q / d t>0$ and vice versa. However, a threshold of specific humidity change of $0.002 \mathrm{~kg} / \mathrm{kg}$ per 6-hours instead of 0 is used to determine moisture uptake $(\mathrm{d} q>0.002 \mathrm{~kg} / \mathrm{kg})$ or release $(\mathrm{d} q \mathrm{~g})$ in order to reduce errors caused by numerical noise and keeps the analysis computationally feasible (James, Stohl et al. 2004, Sodemann, Schwierz et al. 2008).

There are 2 possible activities and 3 kinds of locations in the air particle's path as shown in Fig. 2a. In order to quantify contribution of each evaporation location along a trajectory to the precipitation at the target location, Sodemann, Schwierz et al. (2008) introduced a 'moisture source attribution method'. 
Based on that, Sun and Wang (2014) developed a "areal source-receptor attribution method" to calculate the contribution of an examined source region to the total precipitation in target region. Considering the subject explored in this study, we adapt the latter and make minor modifications here. Instead of tracing back 10 days, the whole simulated time is considered to avoid discrepancy caused by recycling time of moisture over different regions. Detailed computational procedures are presented as follows:

1) Find all air particles that have moisture released (d $q g)$ in the target regions (TR) from model output files and calculate the total moisture release Rtotal (unit: $\mathrm{kg}$ ).

2) Among the air particles selected in step 1, for the i-th examined source region (SR) refer its contribution to the target region as $\mathrm{CON}(\mathrm{i})$. Find all the air particles passing over this region that have uptake of moisture from there $(\mathrm{d} q>0.002 \mathrm{~kg} / \mathrm{kg})$.

3) For j-th air parcel, the computation of its moisture contribution from the i-th SR to precipitation in TCZ $(\mathrm{CON}(\mathrm{i}, \mathrm{j}), \mathrm{unit}$ : $\mathrm{kg})$ is shown in Fig. $2 \mathrm{~b}$. All possible situations should be considered along its way to the target region(Fig. 2a).To begin with, find the first (forward in time) time (T) moisture uptake over the i-th $\mathrm{SR}$, and the moisture mass from i-th $\mathrm{SR}(\Delta$, unit $: \mathrm{kg})$ in this particle at present is $m \mathrm{dq}(\mathrm{T})$ with present moisture contribution $(\mathrm{CON}(\mathrm{i}, \mathrm{j}))$ equals to 0 . The following calculations are detailed in Fig. $2 \mathrm{~b}$.

4) Repeat step 3 on all particles selected in step 2. The absolute (CON(i), unit:kg) and relative moisture contribution (RCON(i), unit:\%)from i-th SR can be given by :

$$
\begin{gathered}
\operatorname{CON}_{(i)}=\sum_{j=0}^{j=J} \operatorname{CON}_{(i, j)}(3) \\
\operatorname{RCON}_{(i)}=\frac{\operatorname{CON}_{(i)}}{\text { Rtotal }} \times 100 \%(4)
\end{gathered}
$$

Where $\mathrm{J}$ is the total number of air particles of step 2 .

\section{Results}

\subsection{Trajectories and E-P diganose}

The average residence time of water vapor in the atmosphere is 10-days according to previous studies (Numaguti 1999). Air particles that released water vapor in TCZ from June to August during 1979-2010 were selected and traced back 10-days. The k-means clustering algorithm is employed to analyze the trajectories of them with the cluster number at 500 (Dorling, Davies et al. 1992). Fig. 3 shows 500 cluster mean trajectories of particles colored with average height above ground level (AGL) and specific humidity change of the particles for the 10 days prior to reaching TCZ during the summers of 1979-2010. The air parcels over TCZ during summer can be divided into 4 main paths: 1)There are some air blocks traveling along the warm anticyclone in the upper troposphere over the Qinghai-Tibet Plateau and North Africa, above $12 \mathrm{~km}$ AGL. 2) A considerable number of particles from the upper atmospheric layers over the North 
Atlantic travel along the latitudes over Europe and Central Asia and reach the TCZ, mostly above $6 \mathrm{~km}$

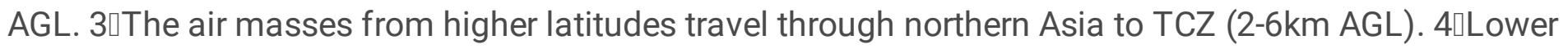
air particles, mainly below $2 \mathrm{~km}$ AGL, enter TCZ from North Indian Ocean or West Pacific Ocean via East Asia. However, for particles comes from first three paths, it is not until they reached Eurasia that they begin uptake water vapor. Particles come from North India Ocean loss moisture when they pass the large water vapor convergence area at the at the southern foothills of the Himalayas. In the meanwhile, the particles come from the Pacific Ocean have been picking up moisture along the way. It is worth noting that the cluster analysis can only show the general information of the trajectories for target air particles and the density of these 500 cluster trajectories can't reflect the intensity of water vapor transport.

Though cluster trajectories give detailed moisture transport paths and water vapor change along the way, it is not enough to identify water vapor sources accurately only based on that. The budget of E-P is calculated to better identify the source-receptor relation. Surface freshwater flux was calculated by a horizontal resolution of $1^{\circ} \times 1^{\circ}$. Fig. 4 shows the mean E-P of all particles selected for the 10 -day period prior to reaching there during the summer of 1979-2010. The positive E-P value can be recognized as a moisture source region where total moisture uptake is stronger than release, while the negative value suggests a moisture sink that involves a net release of moisture. There are approximately seven source regions for the target region, which are most of Eurasia continent in northwest of the TCZ (EC), centraleastern China (CEC), western Pacific Ocean (WPO), South China Sea and Indonesia (SCSI), Bay of Bengal (BOB), Arabian Sea (AS) and local evaporation (TCZ). the southwest of Indian Peninsula, the southern foothills of the Himalayas and the Indo-China Peninsula are water vapor sink areas, consistent with the strong convergence area in Fig. 1, which can be explained by the large terrain blocking the robust Indian summer monsoon. Furthermore, the northwest Eurasia is also featured by positive E-P value, which means air parcels passing this area encounter a large amount of moisture release.

\subsection{Quantification of moisture contribution from source regions}

The summer precipitation time series over TCZ is equivalent to the total moisture release of all air parcels divided by the area of TCZ. To test the performance of simulated precipitation in TCZ, we compared our results from FLEXPART_10.4v model with reanalysis data from JRA-55 and observation daily precipitation from National Meteorological Information Center. The result is shown in Fig. 5. The climatic mean summer (JJA) precipitation calculated from the model in TCZ during $1979-2010$ is $3.07 \mathrm{~mm} /$ day, while those derived from observation and JRA-55 are $2.95 \mathrm{~mm} /$ day and $3.95 \mathrm{~mm} /$ day, respectively. Time series of precipitation anomalies simulated by the model are in good agreement with the reanalysis data and observation data (Fig. 5). The Pearson correlation coefficients between the model output and reanalyzed and observed datasets are 0.58 and 0.66 with significance above $95 \%$ confidence level. However, model simulation results seem to overestimate amplitudes of precipitation anomalies during 1980-1988 and 1998-2005, compared with those derived from observation and reanalyzed datasets. Overall, the model simulation is capable of reproducing the observations and reanalyzed data and reflecting the variation of summer precipitation of TCZ. 
The relative moisture contributions of 7 source regions selected in section 3.1 to the summer precipitation of TCZ during 1979-2010 are calculated with the method described in Section 2.3.The moisture uptake from the source regions (Uptake) by the target air particles that have released water vapor during summer in TCZ was divided into three parts along its way to the target domain: moisture released before reaching TCZ (Loss), the part that reached TCZ but was not released (Unreleased), and water vapor that reached and released in the TCZ, the one making an actual contribution to summer precipitation over TCZ (Contribution). Fig. 6 shows ratios of water vapor uptake in each source region to total TCZ water vapor release in summer which includes moisture released in TCZ, loss en-route and unreleased moisture. The seven examined source regions contribute $71.18 \%$ of water supply, explaining most of the water vapor that contributes to the summer (JJA) precipitation in TCZ from 1979-2010. The continental moisture from TCZ, CEC and EC accounts for $55.11 \%$ of the summertime precipitation, while the oceanic moisture from WPO, SCSI, BOB and AS only accounts for $16.06 \%$ because of a large amount of moisture loss during transit. Local evaporation provides the most water vapor for summer precipitation in TCZ among all source regions (19.96\%).In addition, evaporation over Eurasia and central and eastern China is also the main source of water vapor, accounting for $18.01 \%$ and $17.14 \%$, respectively. Even without taking into account actual contribution to precipitation, continental moisture is still the primary source of water vapor over the transition zone, bringing more moisture (104.64\%) to the TCZ than ocean (31.96\%) during rainy days. However, water vapor uptake (99.99\%) in EC loss a lot (66.95\%) during the transport compared with TCZ and CEC. Despite a large amount of water vapor uptake (119.56\%), western Pacific Ocean is only responsible for $7.46 \%$ of water vapor supply for summer precipitation of TCZ, which is about half of moisture that comes from the ocean. Water vapor from SCSI, BOB and AS is only responsible for $3.56 \%$, $2.55 \%$ and $2.13 \%$ moisture released in TCZ, respectively.

\subsection{The role of different source regions in variation of summer precipitation in TCZ}

Further studying the role of water vapor supply in summer rainfall variation in TCZ is of great significance, particularly for its strong inter-annual climate fluctuation(Wang, Wang et al. 2020). Fig. 7 shows the water vapor contribution of each region under different summer precipitation during 19792010. Generally, as precipitation increase, the contributions from all 7 source regions exhibit an upward tendency, especially in the land regions (EC, CEC and local evaporation). Local evaporation is not only the greatest moisture supplier, but also with the largest increase with precipitation. Among the four ocean sources, WPO contributes the most moisture. However, when rainfall is relative small (less than $2.6 \mathrm{~mm} /$ day), water vapor from Western Pacific remains roughly constant irrespective of summer precipitation in TCZ, unlike other source regions.

For better understanding of which source region should take primary responsibility for the summer rainfall variation in TCZ, we also conduct a Pearson linear correlation analysis of water vapor uptake amount and absolute moisture contributions from 7 source regions against summer precipitation simulated by the model (Table 1). The correlation coefficient between the sum of water vapor released $s$ in the target region from all selected source and precipitation in the transition zone is 0.96 , which means 
moisture contributions from the selected source areas can well capture precipitation changes. All correlation scores in the Table 1 show significant positive correlation between water vapor from 7 source regions and precipitation, with correlation coefficient ( $r$ ) varying from 0.51 to 0.77 . The correlation between moisture from local evaporation and summer precipitation is the greatest with $r=0.77$. The correlation coefficient of water vapor uptake from WPO is 0.88 , indicating the importance of evaporation in WPO in shaping dry-wet condition of TCZ during summer. However, the correlation coefficient for moisture released is only 0.59 . Although the moisture from SCSI contributes $2.31 \%$ to the summer precipitation of TCZ (Fig. 6), the correlation coefficient between them is 0.77 , which means water vapor from SCSI plays an important role in summer rainfall variation in TCZ.

Table 1

Pearson linear correlation coefficient between precipitation in TCZ and absolute moisture contribution from source regions or the total moisture uptake amount over source regions.

\begin{tabular}{|lllllllll|}
\hline & EC & CEC & WPO & SCSI & BOB & AS & TCZ & Total \\
\hline Uptake & 0.73 & 0.55 & 0.88 & 0.71 & 0.72 & 0.75 & 0.69 & 0.96 \\
Contribution & 0.61 & 0.76 & 0.51 & 0.77 & 0.68 & 0.65 & 0.77 & 0.95 \\
\hline
\end{tabular}

We also select wet/dry years of summer in TCZ based on normalized summer precipitation above 0.75 standard deviation (Fig. 8, Table 2) to further explore how moisture contribution change from 7 regions in different climate conditions. The average moisture contributions from different regions in dry and wet years to summer precipitation in TCZ are compared in Fig. 9, along with total water vapor uptake and loss en-route and unreleased water vapor. Compared with dry years, the moisture contribution from each source region increased uniformly and significantly in wet years, leading to the ample precipitation. The water vapor released in TCZ from land has increased much more than that from the sea, especially for the local evaporation. Therefore, moisture recycled from land takes more responsibility for interannual variability of summer precipitation. However, there is little difference between ocean and land when it comes to water vapor uptake amount. CEC, as one of the main sources of water vapor, has the smallest increment in moisture uptake, but its contribution to the TCZ transition zone is still quite a lot because of its little change in loss and unreleased water vapor amount. Although the absorption of water vapor increases in WPO during wet years, so does the moisture loss along the way. The increase of released moisture from WPO is not as great as that of land sources.

Table 2

Wet years and dry years selected according to summer precipitation during $1979-2010$

\section{year}

Dry year 1993 / 1997 / 1999/2000 / 2001 / 2002 / 2003 / 2004 / 2007

Wet year 1983 / 1984 /1985/ 1987 / 1988 / 1990 / 1994 


\subsection{The qualified impact of the monsoon system and the middle and high latitude system}

As an interface area between monsoon circulation and systems in the middle and high latitude, there have been evidence showing that summer rainfall in TCZ are mainly influenced by these two climate systems(Simmonds, Bi et al. 1999, Huang, Liu et al. 2011). Model sensitive experiments conducted by Zhao, Chen et al. (2019) and Piao, Chen et al. (2017) showed that SST anomalies in the tropical centraleastern Pacific and the NTA are both key drivers for inter-annual and decadal variations of precipitation over the MTZ in China during summer. Wang, Wang et al. (2020) suggested that wet/dry condition also influenced by EASM circulation and pressure anomaly over Mongolian area. However, since the interaction between the westerly precipitation and monsoon rainfall is more complex (Qian, Ding et al. 2009), it is hard to determine the dominant system influencing wet-dry condition of TCZ. Here, the Lagrange method provides us a new perspective to solve this problem by figuring out which one is the major influential factor. Among the seven regions, water vapor from CEC, WPO, SCSI, AS and BOB is inextricably linked to monsoon system, while EC is tied to the mid-latitude westerlies. The precipitation generated by moisture contributed by monsoon system, middle and higher latitude system and local evaporation is shown in Fig. 8. Monsoon circulation is the main provider of water vapor for summer rainfall in TCZ, contributing 33.2\% moisture summed by contributions from CEC, WPO, SCSI, AS and BOB. Summer rainfall caused by moisture from the area controlled by westerlies (EC) is $18.01 \%$, while the local evaporation contributes $19.96 \%$. The Pearson linear correlation coefficient of summer rainfall related to monsoon system, the westerlies and local evaporation are $0.84,0.61$ and 0.77 , respectively, which all pass the significant test with the significant level of 0.05 . The differences in the average contribution between the wet years and dry years (wet year minus dry year) driven by summer monsoon, westerlies and local evaporation are illustrated in Fig. 10, as well as the total moisture uptake, en-route loss and unreleased water vapor. In wet years, the average water vapor absorption in monsoon regions is $4.49 \times 10^{14} \mathrm{~kg}$ more than that in dry years, followed by westerlies dominant area $\left(2.16 \times 10^{14} \mathrm{~kg}\right)$ and local evaporation $\left(1.31 \times 10^{14} \mathrm{~kg}\right)$. Absolute moisture contribution from the monsoon system also rises by the largest amount between the wet years and dry years, exceeding $0.63 \times 10^{14} \mathrm{~kg}$, narrowly outweighting the local evaporation $\left(0.59 \times 10^{14} \mathrm{~kg}\right)$, because of a huge amount en-route loss $\left(3.44 \times 10^{14} \mathrm{~kg}\right)$. Released moisture conveyed by the mid-latitude westerlies only increases $0.35 \times 10^{14} \mathrm{~kg}$ per year for the same reason. In conclusion, moisture related with monsoon system contributes the most of summer rainfall in TCZ during 1979-2010, and also has the greatest impact on interannual variability. Local evaporation followed, and finally the middle and higher latitudes system.

\section{Concluding Remarks}

Air particles that reached TCZ during summer mainly travel through four paths. As for the air blocks in the upper troposphere, plenty of them come from the North Atlantic to TCZ along with the mid-latitude westerlies. Some of them travel along the warm anticyclone in the upper troposphere over the QinghaiTibet Plateau and North Africa. Some of the air parcels in the middle and lower layers over TCZ come 
from regions of higher latitudes via northern Asia, with others from the Indian Ocean and the western Pacific Ocean.

Summer precipitation and its interannual variation is well reproduced by FLEXPART_10.4v. Seven moisture source regions are identified based on E-P diagnosis, which are responsible for over $70 \%$ summer precipitation over TCZ during 1979-2010. The moisture contribution to summer precipitation in TCZ from land region is greater than that from the ocean. Local evaporation has the greatest moisture source for precipitation, followed by the Eurasian continent and central and eastern China. And there is a mass of moisture taken up in WPO which is the most in all selected regions. Nevertheless, only about 7\% of the water vapor contributed to summer precipitation in TCZ comes from WPO, and correlation analysis also shows relatively small correlation with the summer precipitation. Most of the water vapor in regions loss in transit like CEC. Moisture increment between wet years and dry years from land is much greater than that from ocean, especially local region, which may be caused by the positive feedback of local precipitation and evaporation.

The Lagrange method make it possible to quantify the influences of different systems to the precipitation in TCZ. Westerlies precipitation and monsoon precipitation are distinguished according to the dominant system of water vapor source region. Summer rainfall related with monsoon system which comes from WPO, SCSI, BOB, AS and CEC is much more than that travels along with westerlies (EC). At the same time, the correlation analysis also shows a closer connection between summer precipitation and summer monsoon in TCZ, compared with the mid-high latitude systems. Compared with dry year, water vapor from regions associated with the monsoon system in wet year significantly increase, while the increment of westerlies precipitation is relatively small, which further indicates that the summer monsoon plays a more important role on the interannual variation of precipitation in TCZ.

\section{Declarations}

Acknowledgement: This work was supported by the National Natural Science Foundation of China Grants Nos. 41875115, 41961144016, 42175041 and 41831175, STEP (2019QZKK0102) and Key Deployment Project of Centre for Ocean Mega-Research of Science, Chinese Academy of Sciences (COMS2019Q03).

\section{References}

1. Chen W, Wang L, Feng J, Wen Z, Ma T, Yang X, Wang C (2019) Recent Progress in Studies of the Variabilities and Mechanisms of the East Asian Monsoon in a Changing Climate. Adv Atmos Sci 36(9):887-901

2. Cohen MD, Stunder BJB, Rolph GD, Draxler RR, Stein AF, Ngan F (2015) NOAA's HYSPLIT Atmospheric Transport and Dispersion Modeling System. Bull Am Meteorol Soc 96(12):2059-2077

3. Dorling SR, Davies TD, Pierce CE (1992) Cluster-Analysis - a Technique for Estimating the Synoptic Meteorological Controls on Air and Precipitation Chemistry - Method and Applications. Atmospheric Environment Part a-General Topics 26(14):2575-2581 
4. Drumond A, Nieto R, Hernandez E, Gimeno L (2011) A Lagrangian analysis of the variation in moisture sources related to drier and wetter conditions in regions around the Mediterranean Basin. Nat Hazards Earth Syst Sci 11(8):2307-2320

5. Hao Y, Zhihong J, Zhengyu L, Qiang Z (2014) Analysis of climatic characteristics of water vapor transport based on the Lagrangian method: A comparison between Meiyu in the Yangtze-Huaihe River region and the Huaibei rainy season. Chinese Journal of Atmospheric Sciences 38(5):965-973

6. Harada Y, Kamahori H, Kobayashi C, Endo H, Kobayashi S, Ota Y, Onoda H, Onogi K, Miyaoka K, Takahashi K (2016) The JRA-55 Reanalysis: Representation of Atmospheric Circulation and Climate Variability. Journal of the Meteorological Society of Japan Ser II 94(3):269-302

7. He C, Zhou W (2020) Different Enhancement of the East Asian Summer Monsoon under Global Warming and Interglacial Epochs Simulated by CMIP6 Models: Role of the Subtropical High. J Clim 33(22):9721-9733

8. Huang G, Liu Y, Huang R (2011) The interannual variability of summer rainfall in the arid and semiarid regions of Northern China and its association with the northern hemisphere circumglobal teleconnection. Adv Atmos Sci 28(2):257-268

9. Huang J, Li Y, Fu C, Chen F, Fu Q, Dai A, Shinoda M, Ma Z, Guo W, Li Z, Zhang L, Liu Y, Yu H, He Y, Xie Y, Guan X, Ji M, Lin L, Wang S, Yan H, Wang G (2017) Dryland climate change: Recent progress and challenges. Rev Geophys 55(3):719-778

10. Huang J, Ma J, Guan X, Li Y, He Y (2019) Progress in Semi-arid Climate Change Studies in China. Adv Atmos Sci 36(9):922-937

11. Huang J, Zhang G, Zhang Y, Guan X, Wei Y, Guo R (2020) Global desertification vulnerability to climate change and human activities. Land Degradation \& Development 31(11):1380-1391

12. Huang R, Liu Y, Feng $T$ (2012) Interdecadal change of summer precipitation over Eastern China around the late-1990s and associated circulation anomalies, internal dynamical causes. Chin Sci Bull 58(12):1339-1349

13. James P, Stohl A, Spichtinger N, Eckhardt S, Forster C (2004) Climatological aspects of the extreme European rainfall of August 2002 and a trajectory method for estimating the associated evaporative source regions. Nat Hazards Earth Syst Sci 4(5-6):733-746

14. Kobayashi S, Ota Y, Harada Y, Ebita A, Moriya M, Onoda H, Onogi K, Kamahori H, Kobayashi C, Endo H, Miyaoka K, Takahashi K (2015) The JRA-55 Reanalysis: General Specifications and Basic Characteristics. Journal of the Meteorological Society of Japan Ser II 93(1):5-48

15. Li Y, Huang JP, Ji MX, Ran JJ (2015) Dryland expansion in northern China from 1948 to 2008. Adv Atmos Sci 32(6):870-876

16. Lu W, Jia GS (2013) Fluctuation of farming-pastoral ecotone in association with changing East Asia monsoon climate. Clim Change 119(3-4):747-760

17. Nieto R, Gimeno L, Trigo RM (2006) A Lagrangian identification of major sources of Sahel moisture. Geophys Res Lett 33(18):L18707 
18. Numaguti A (1999) Origin and recycling processes of precipitating water over the Eurasian continent: Experiments using an atmospheric general circulation model. Journal of Geophysical Research: Atmospheres 104(D2):1957-1972

19. Oshima K, Tachibana Y, Hiyama T (2015) Climate and year-to-year variability of atmospheric and terrestrial water cycles in the three great Siberian rivers. Journal of Geophysical Research: Atmospheres 120(8):3043-3062

20. Ou TH, Qian WH (2006) Vegetation variations along the monsoon boundary zone in East Asia. Chinese Journal of Geophysics 49(3):698-705

21. Peng D, Zhou T, Zhang L (2020) Moisture Sources Associated with Precipitation during Dry and Wet Seasons over Central Asia. J Clim 33(24):10755-10771

22. Piao J, Chen W, Wei K, Liu Y, Graf H-F, Ahn J-B, Pogoreltsev A (2017) An abrupt rainfall decrease over the Asian inland plateau region around 1999 and the possible underlying mechanism. Adv Atmos Sci 34(4):456-468

23. Pisso I, Sollum E, Grythe H, Kristiansen NI, Cassiani M, Eckhardt S, Arnold D, Morton D, Thompson RL, Groot CD, Zwaaftink N, Evangeliou H, Sodemann L, Haimberger S, Henne D, Brunner JF, Burkhart A, Fouilloux J, Brioude A, Philipp P, Seibert, Stohl A (2019) The Lagrangian particle dispersion model FLEXPART version 10.4. Geosci Model Dev 12(12):4955-4997

24. Qian C, Wu Z, Fu C, Zhou T (2010) On multi-timescale variability of temperature in China in modulated annual cycle reference frame. Adv Atmos Sci 27(5):1169-1182

25. Qian W, Ding T, Hu H, Lin X, Qin A (2009) An overview of dry-wet climate variability among monsoonwesterly regions and the monsoon northernmost marginal active zone in China. Adv Atmos Sci 26(4):630-641

26. Saha S, Moorthi S, Pan H-L, Wu X, Wang J, Nadiga S, Tripp P, Kistler R, Woollen J, Behringer D, Liu H, Stokes D, Grumbine R, Gayno G, Wang J, Hou Y-T, Chuang H-y, Juang H-MH, Sela J, Iredell M, Treadon R, Kleist D, Van Delst P, Keyser D, Derber J, Ek M, Meng J, Wei H, Yang R, Lord S, van den Dool H, Kumar A, Wang W, Long C, Chelliah M, Xue Y, Huang B, Schemm J-K, Ebisuzaki W, Lin R, Xie P, Chen M, Zhou S, Higgins W, Zou C-Z, Liu Q, Chen Y, Han Y, Cucurull L, Reynolds RW, Rutledge G, Goldberg M (2010) The NCEP Climate Forecast System Reanalysis. Bulletin of the American Meteorological Society 91(8):1015-1058

27. Salih AAM, Zhang Q, Pausata FSR, Tjernström M (2016) Sources of Sahelian-Sudan moisture: Insights from a moisture-tracing atmospheric model. Journal of Geophysical Research: Atmospheres 121(13):7819-7832

28. Salih AAM, Zhang Q, Tjernström M (2015) Lagrangian tracing of Sahelian Sudan moisture sources. Journal of Geophysical Research: Atmospheres 120(14):6793-6808

29. Simmonds I, Bi DH, Hope $P$ (1999) Atmospheric water vapor flux and its association with rainfall over China in summer. J Clim 12(5):1353-1367

30. Sodemann H, Schwierz C, Wernli H (2008) Interannual variability of Greenland winter precipitation sources: Lagrangian moisture diagnostic and North Atlantic Oscillation influence. Journal of 
Geophysical Research-Atmospheres 113:D3

31. Stohl A, James P (2004) A Lagrangian analysis of the atmospheric branch of the global water cycle. part I: Method description, validation, and demonstration for the August 2002 flooding in central Europe. J Hydrometeorol 5(4):656-678

32. Sun B, Wang H (2014) Moisture Sources of Semiarid Grassland in China Using the Lagrangian Particle Model FLEXPART. J Clim 27(6):2457-2474

33. Trenberth KE, Guillemot CJ (1995) Evaluation of the Global Atmospheric Moisture Budget as Seen from Analyses. J Clim 8(9):2255-2272

34. Wang L, Chen W (2014) A CMIP5 multimodel projection of future temperature, precipitation, and climatological drought in China. Int J Climatol 34(6):2059-2078

35. Wang L, Chen W, Huang G, Zeng G (2017) Changes of the transitional climate zone in East Asia: past and future. Clim Dyn 49(4):1463-1477

36. Wang Q, Wang L, Huang G, Piao J, Chotamonsak C (2020) Temporal and spatial variation of the transitional climate zone in summer during 1961-2018. Int J Climatol 41(3):1633-1648

37. Wang S, Zuo H, Zhao S, Zhang J, Lu S (2017) How East Asian westerly jet's meridional position affects the summer rainfall in Yangtze-Huaihe River Valley? Clim Dyn 51(11-12):4109-4121

38. Wang W, Li H, Wang J, Hao X (2020) Water Vapor from Western Eurasia Promotes Precipitation during the Snow Season in Northern Xinjiang, a Typical Arid Region in Central Asia.Water12(1)

39. Xu Y, Zhao P, Si D, Cao L, Wu X, Zhao Y, Liu N (2019) Development and preliminary application of a gridded surface air temperature homogenized dataset for China. Theoret Appl Climatol 113:505-516

40. Zhao W, Chen W, Chen S, Nath D, Wang L (2020) Interdecadal change in the impact of North Atlantic SST on August rainfall over the monsoon transitional belt in China around the late 1990s. Theoret Appl Climatol 140(1-2):503-516

41. Zhao W, Chen W, Chen S, Yao S-L, Nath D (2019) Inter-annual variations of precipitation over the monsoon transitional zone in China during August-September: Role of sea surface temperature anomalies over the tropical Pacific and North Atlantic.Atmospheric Science Letters20(1)

42. Zhihong J, Wei R, Zhengyu L (2013) and Y. hao Analysis of Water Vapor transport characteristics during the Meiyu over the Yangzi-Huaihe river valley using theLagrangian method. Acta Meteorologica Sinica 71(2): 295-304

43. Zhu X, Wu T, Hu G, Wang S, Wu X, Li R, Wang W, Wen A, Ni J, Li X, Hao J (2020) Long-distance atmospheric moisture dominates water budget in permafrost regions of the Central Qinghai-Tibet plateau. Hydrol Process 34(22):4280-4294

\section{Figures}




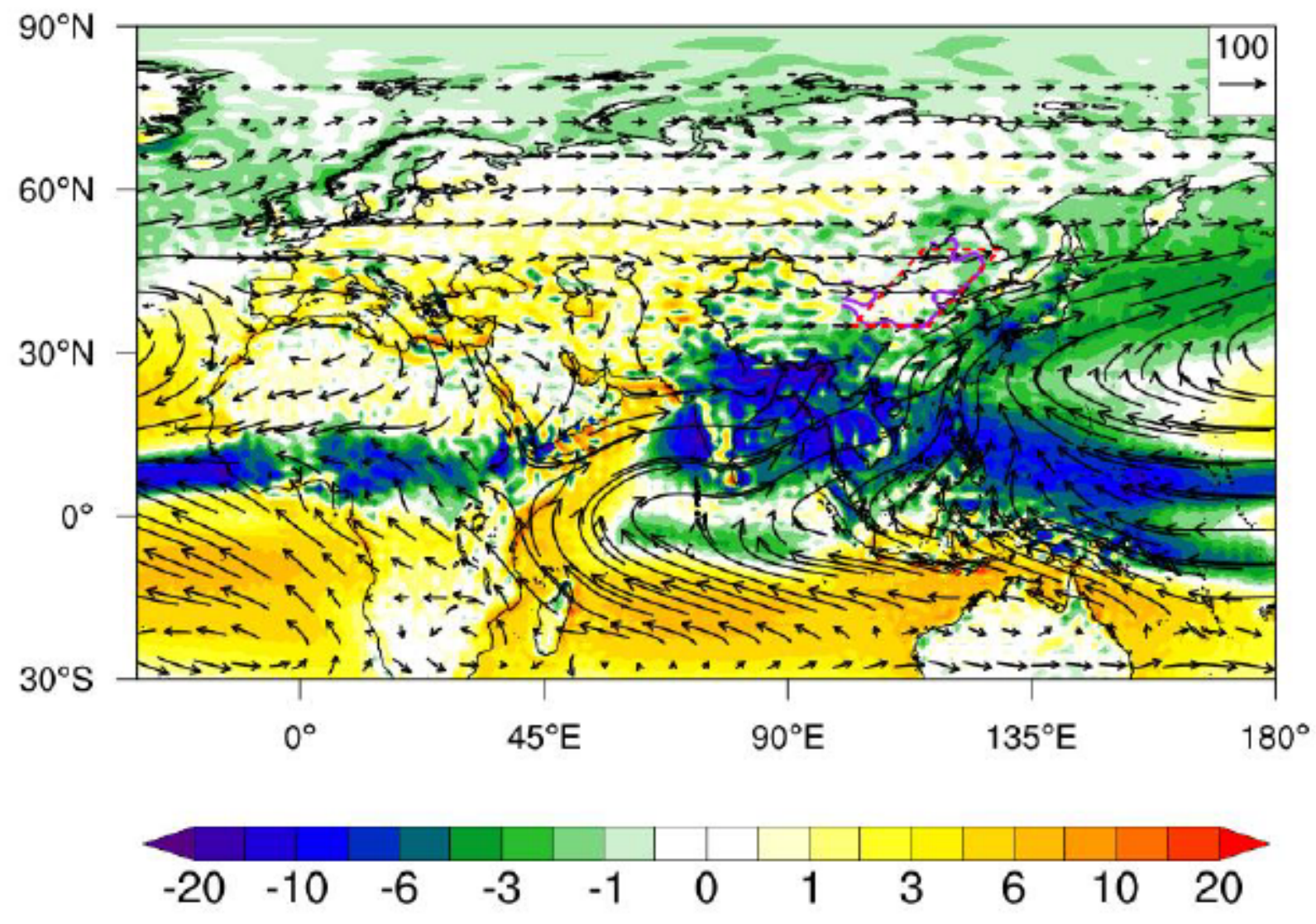

Figure 1

Vertically integrated water vapor flux (arrows, units: $\mathrm{kg} \cdot \mathrm{m}-1 \cdot \mathrm{s}-1$ ) and its divergence (contour, units: 10 $5 \mathrm{~kg} \cdot \mathrm{m}-2 \cdot \mathrm{s}-1$ ) in TCZ during June-August of 1979-2010. Geographical position of summer TCZ (thick purple solid line) identified with SM_Al by Wang, Wang et al. (2020) and its simplified boundary (red dashed line). 
a)

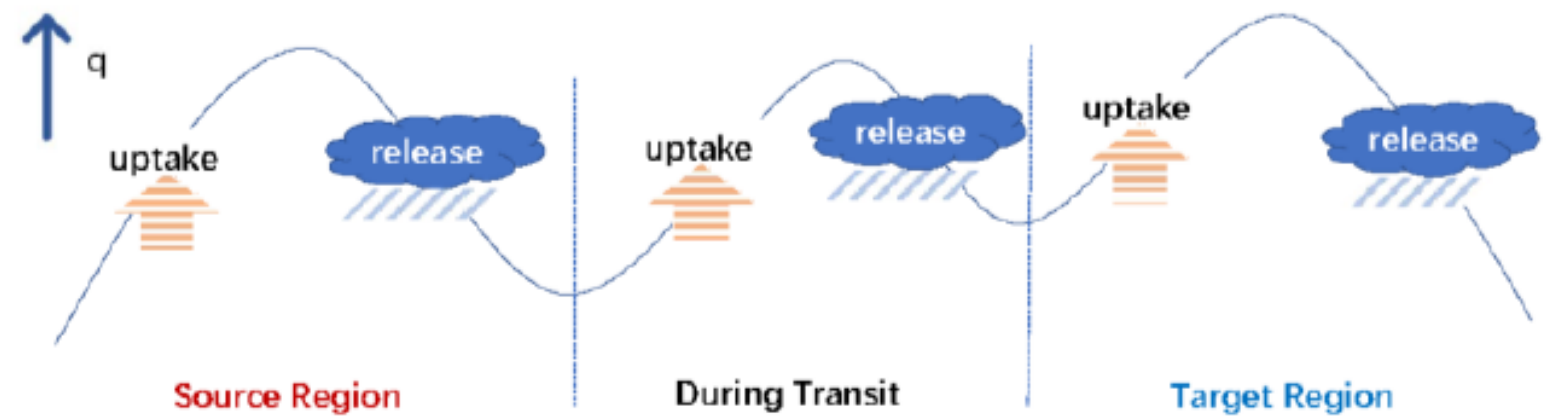

b)

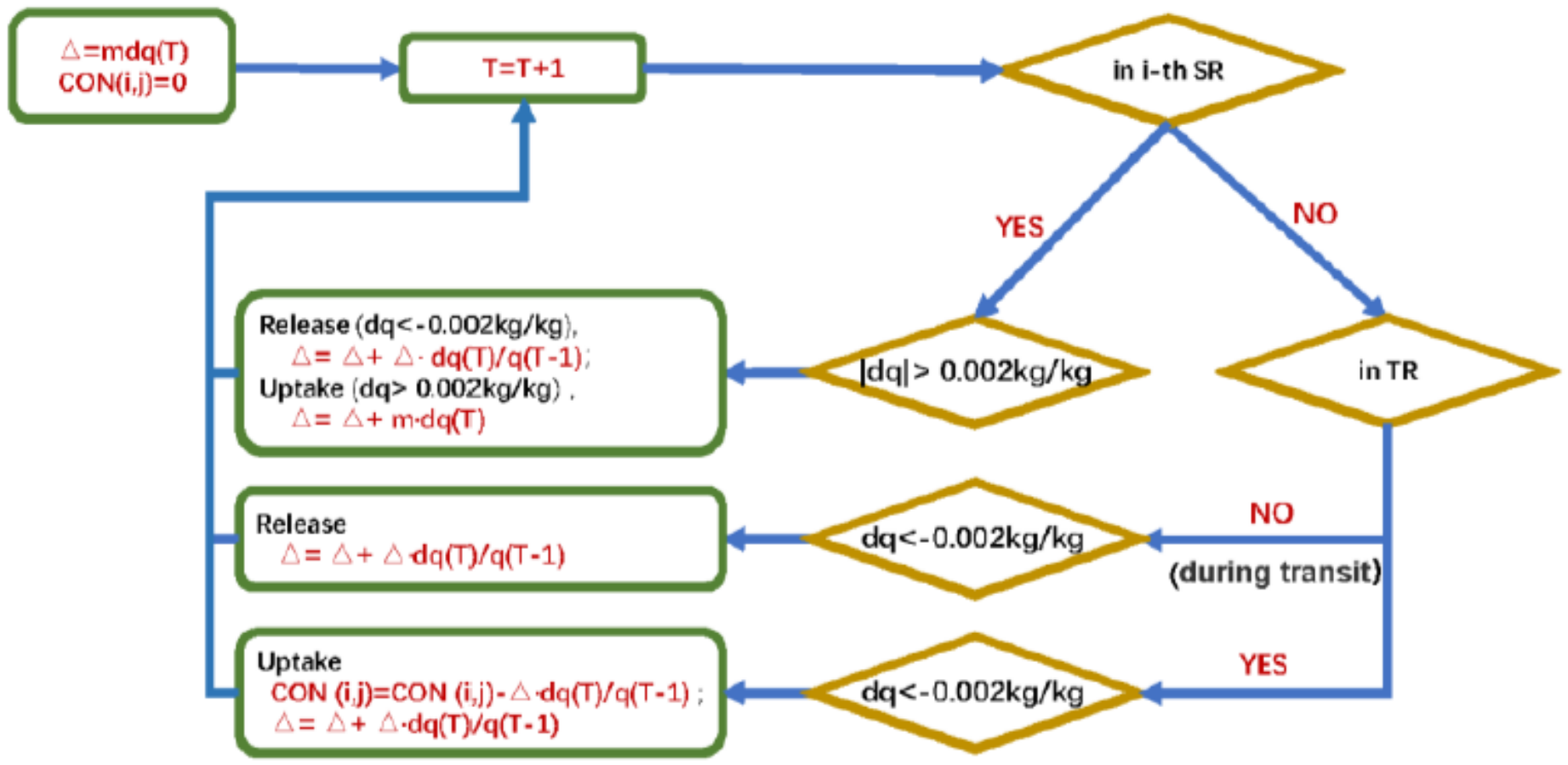

\section{Figure 2}

a)possible situations an air particles may occur before it reaches target region. b) Calculation process of absolute moisture contribution of the j-th air particle uptake from i-th source region to the precipitation in

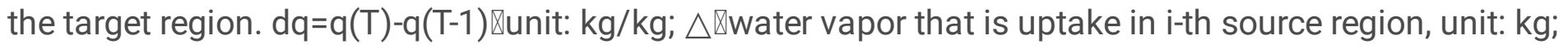
CON(i囚j): accumulated water vapor from i-th source region released in the target area by air block i, unit: $\mathrm{kg}$. 

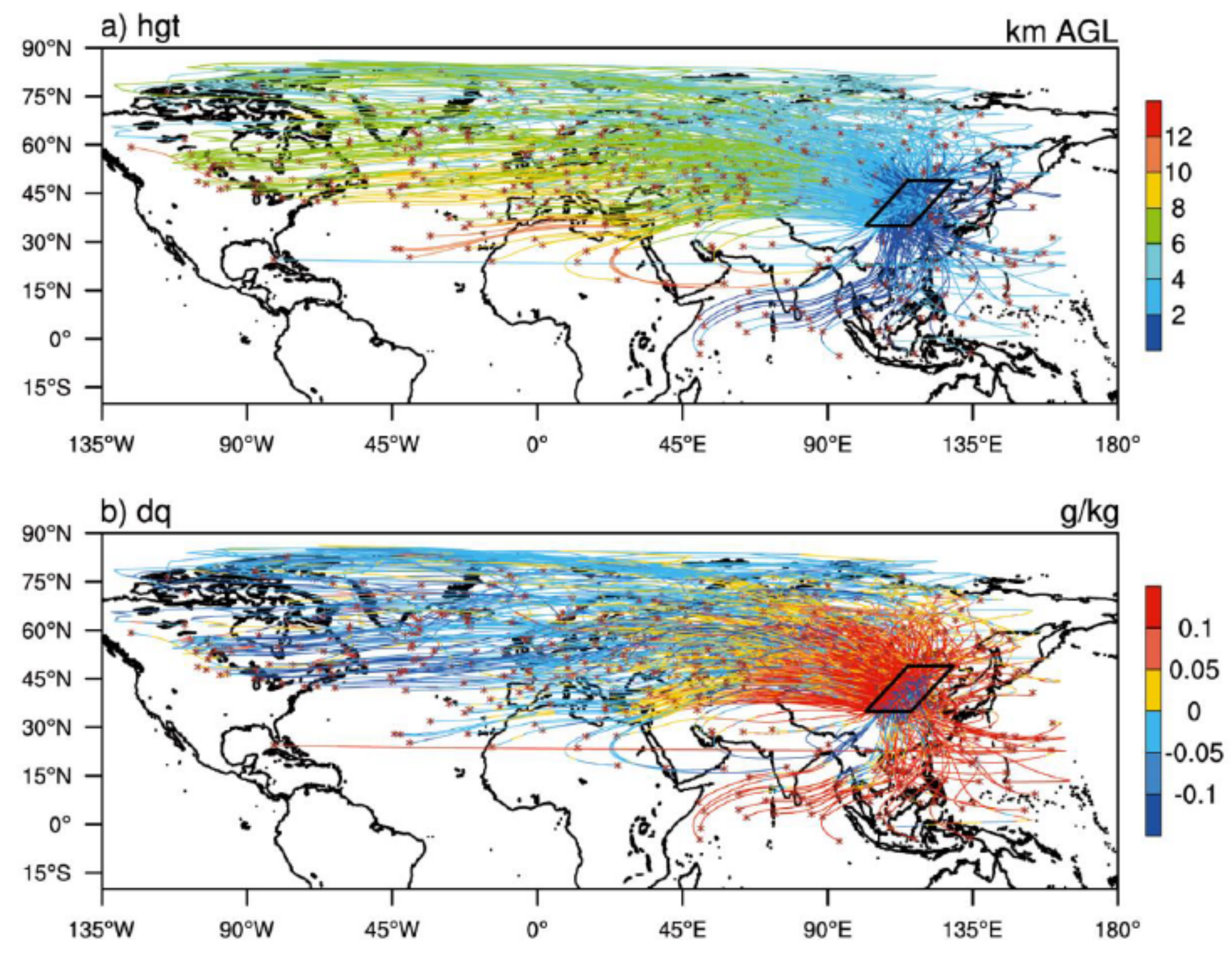

Figure 3

Cluster mean trajectories (number: 500 ) of particles for the 10 days prior to reaching TCZ in the summers of 1979-2010. a)The trajectories are colored according to the altitudes above ground level (units: $\mathrm{m}$ $A G L)$. b) colored according to the specific humility change(dq,units: $\mathrm{g} / \mathrm{kg})$. The target region TCZ is expressed by the polygon in bold black. 


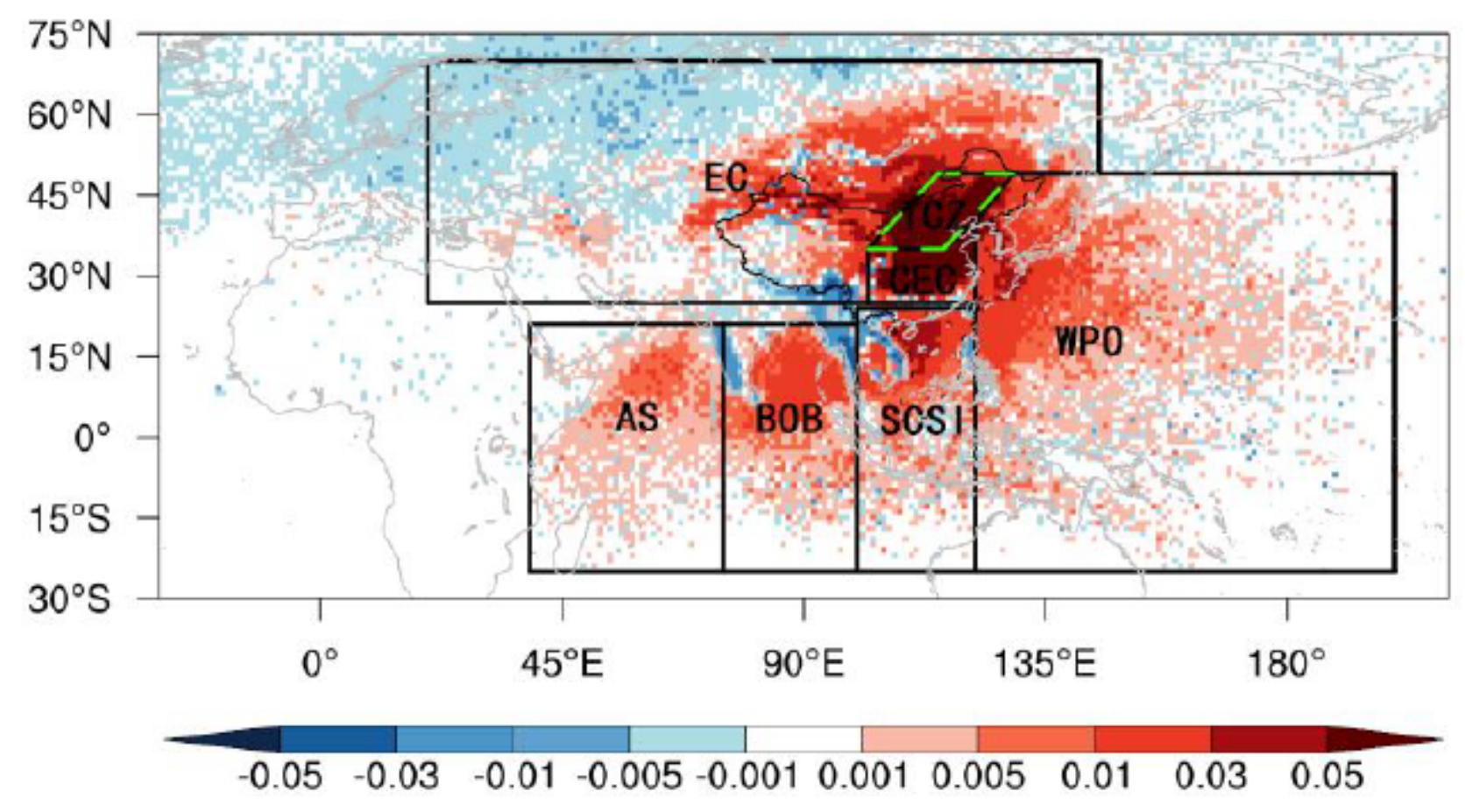

Figure 4

Mean E-P (unit: $\mathrm{mm} /$ day) of target-bound air parcels in 1-10 days before reaching TCZ during JuneAugust of 1979-2010.

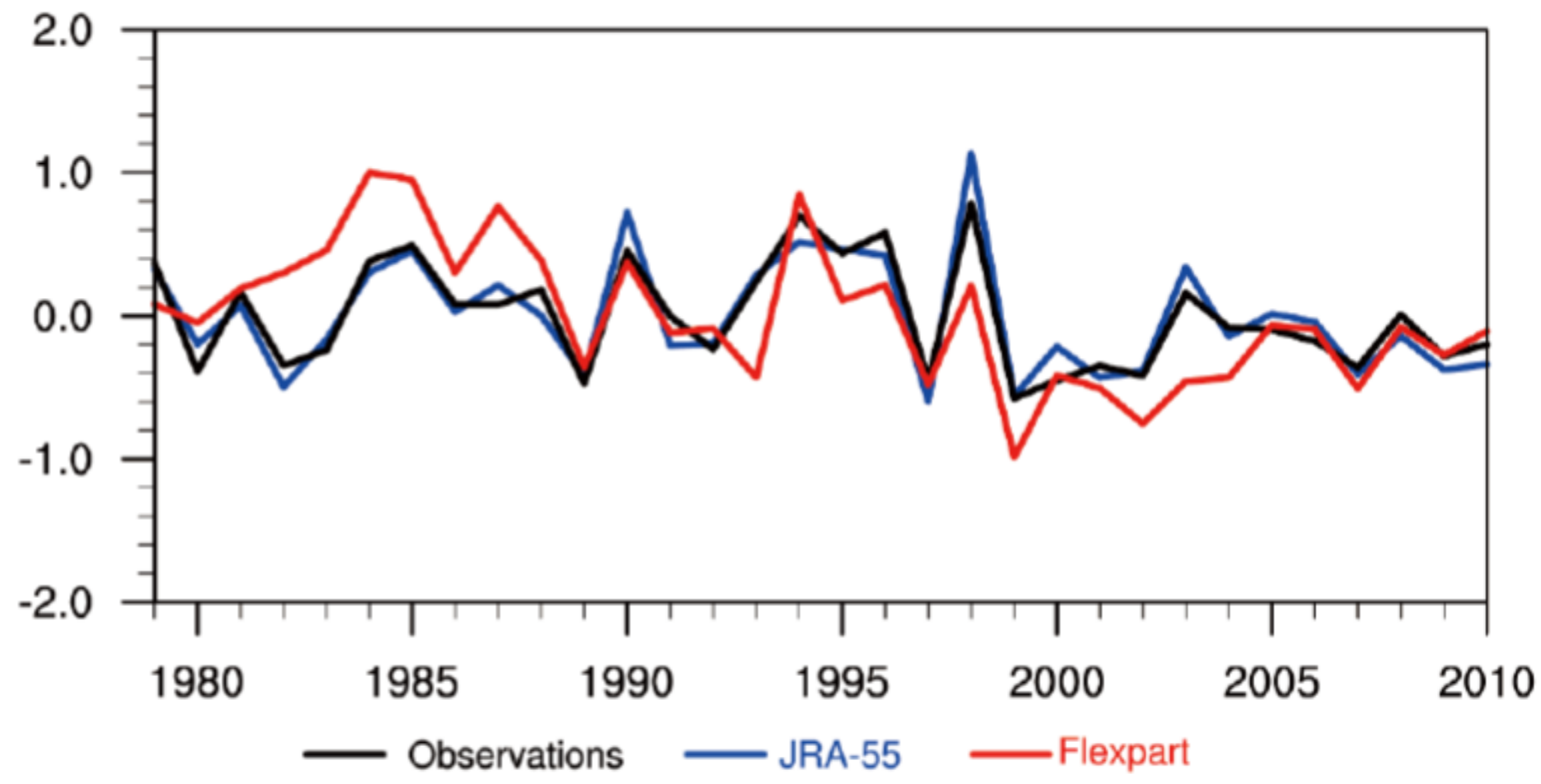

Figure 5 
Time series of summer precipitation (JJA) anomaly (units:mm/day) in TCZ during 1979-2010 simulated by FLEXPART (red solid line),compared with JRA-55 reanalyzed data (blue) and observation data from CMA(black).

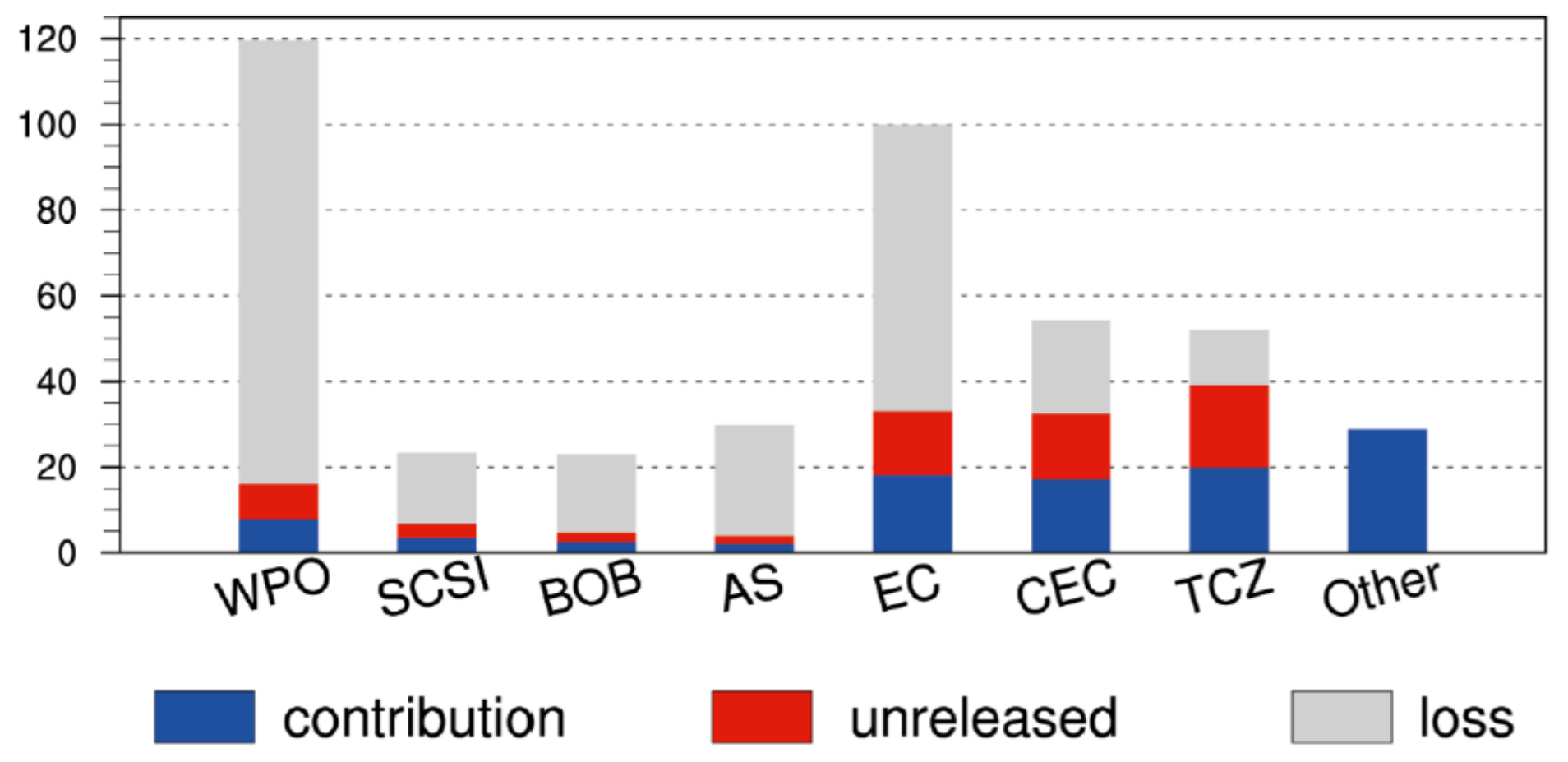

Figure 6

The ratios of the moisture uptake from the seven examined source areas and other area to the total moisture release in the TCZ during June-August (unit: \%), which consist of three parts: the part lost enroute (loss, grey bar), the part that reached the target domain but was not released (unreleased, red bar), and the part that was released over the target domain (released, blue bar). 

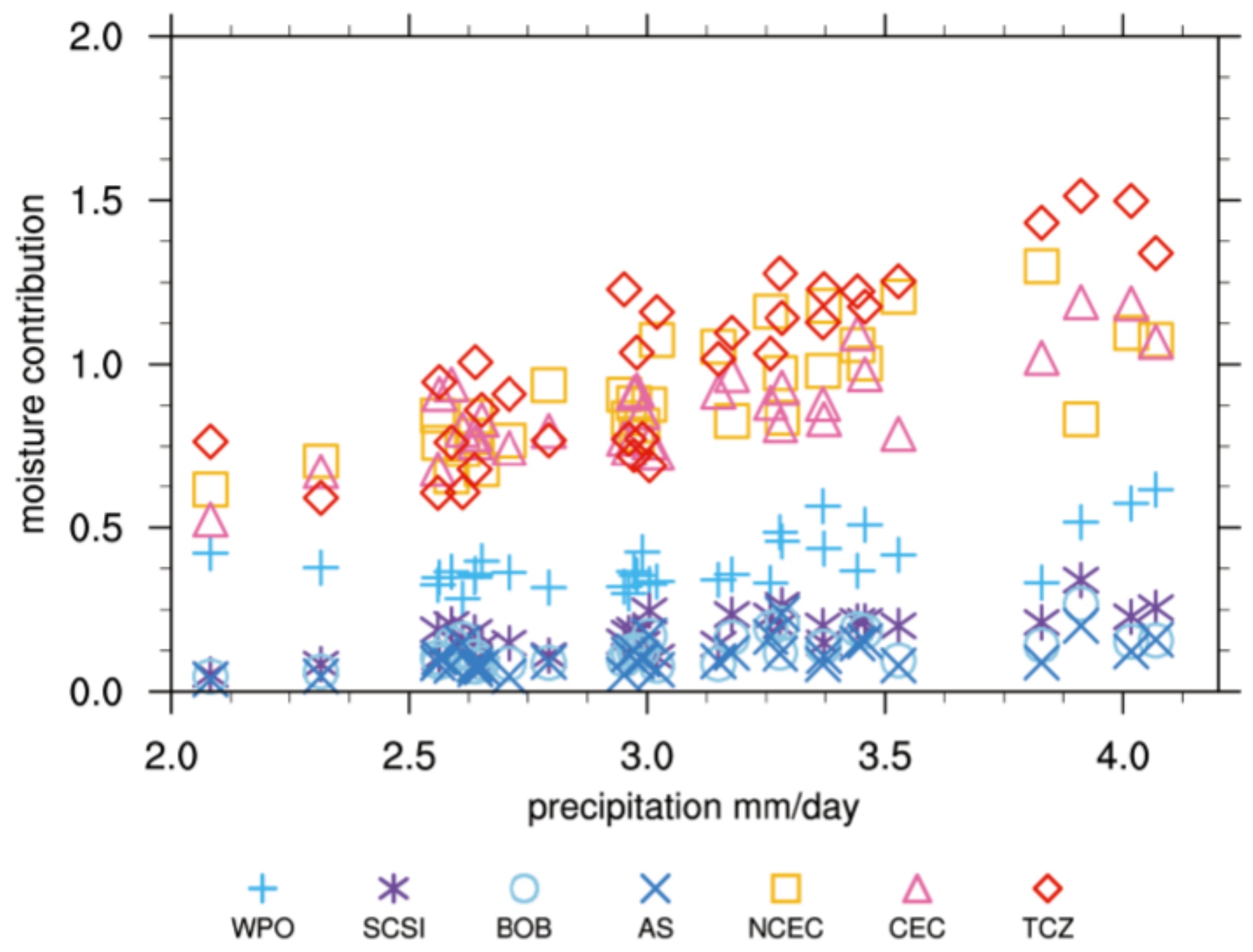

Figure 7

Scatter diagram of model simulated summer rainfall (units: mm/day) during 1979-2010 versus water vapor contributions(units: $1014 \mathrm{~kg}$ ) from seven resource region 


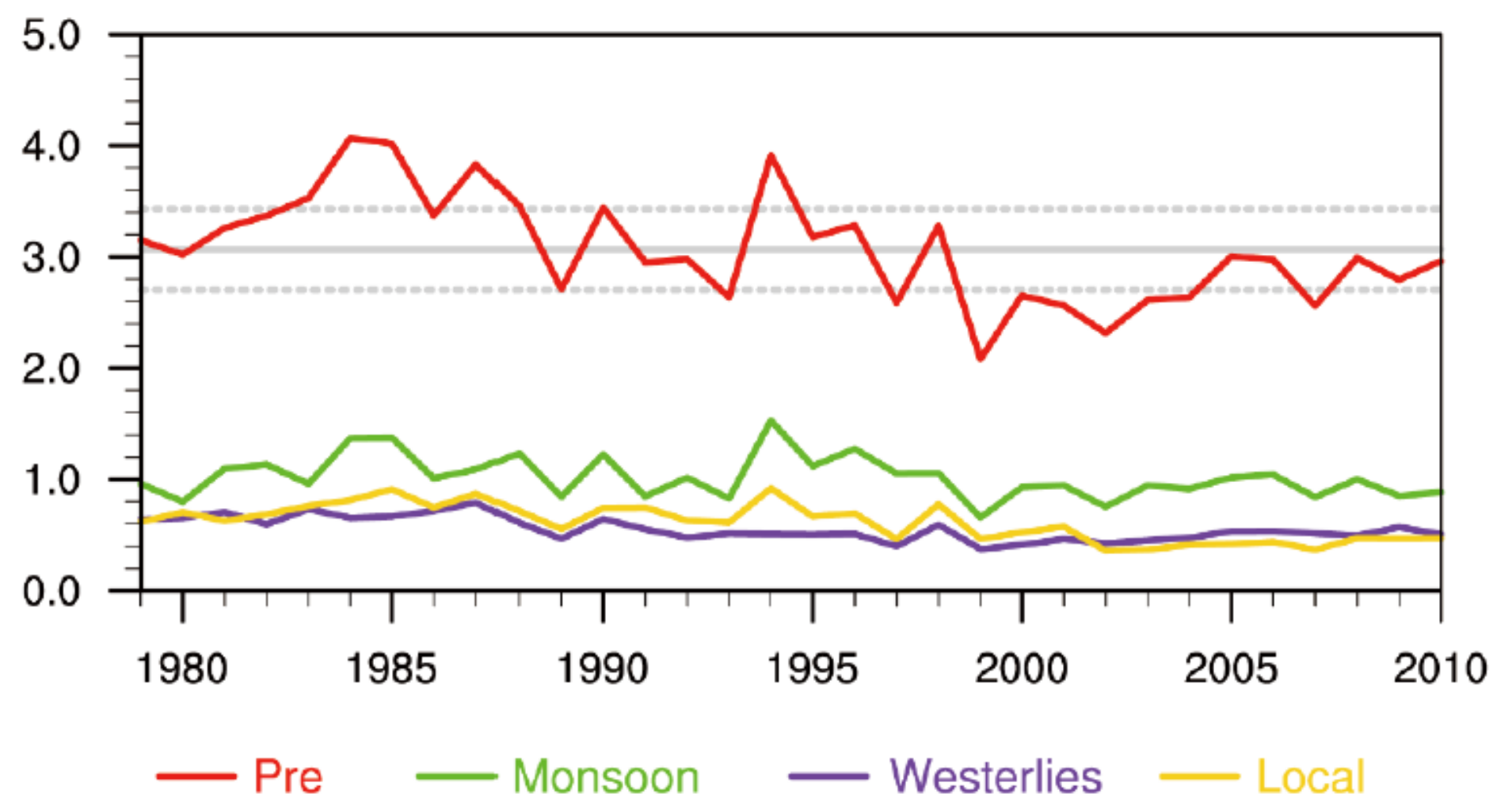

Figure 8

Time series of summer precipitation (JJA) (units:mm/day) in TCZ during 1979-2010 simulated by FLEXPART (red solid line) and its average (grey solid line), as well as summer rainfall contibuted by regions related with monsoon system (purple), Westerlies(purple) and local evaporation (yellow). 
b) contribution
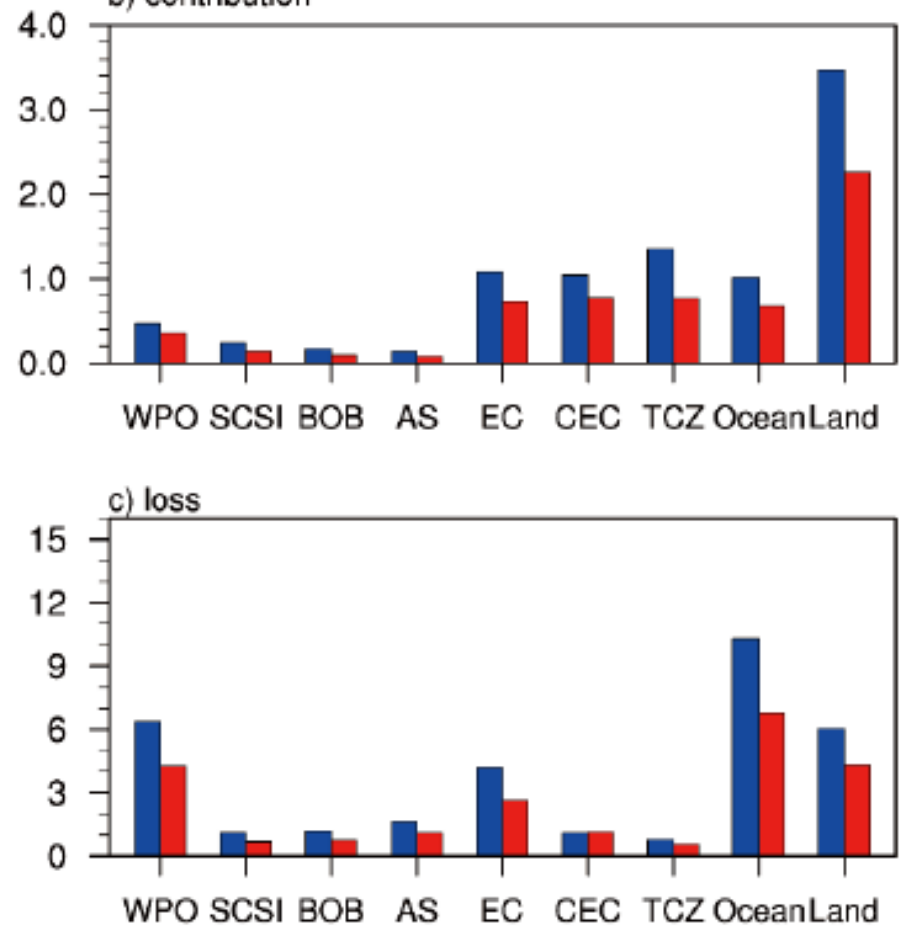

wet year

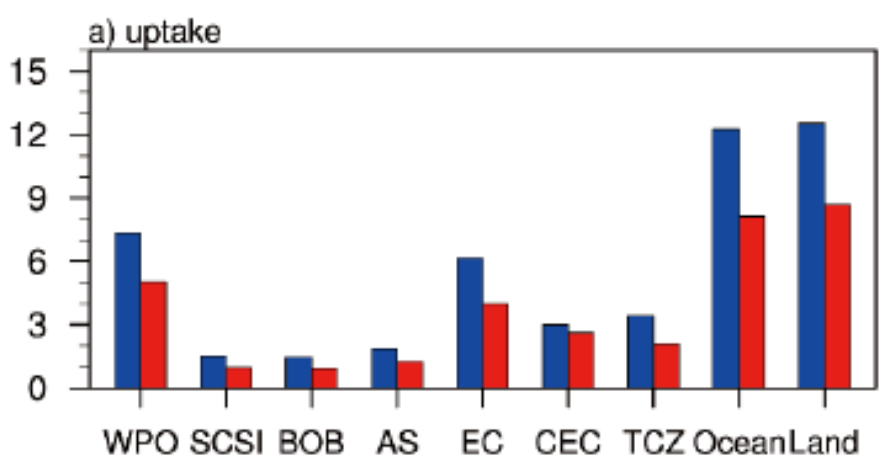

d) unreleased

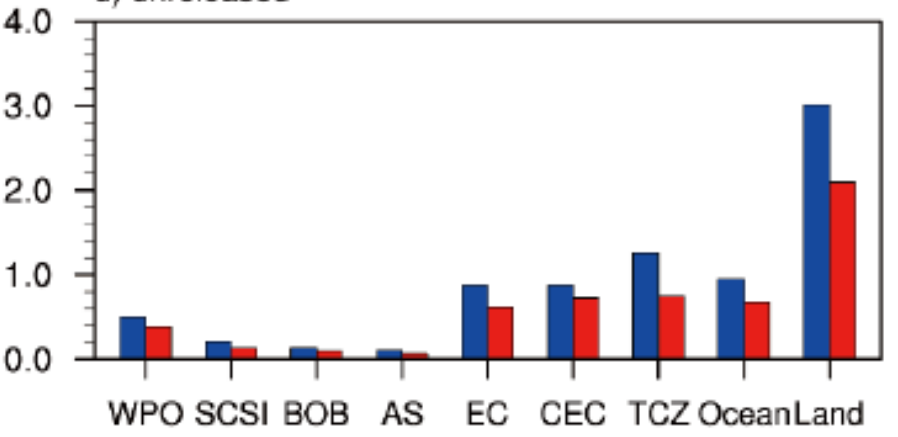

dry year

Figure 9

a) Moisture absolute contribution to summer precipitation during 1979-2010 from seven source regions (units:1014kg), as well as b) total moisture uptake in source regions, c) loss during transport, and d) unreleased moisture.

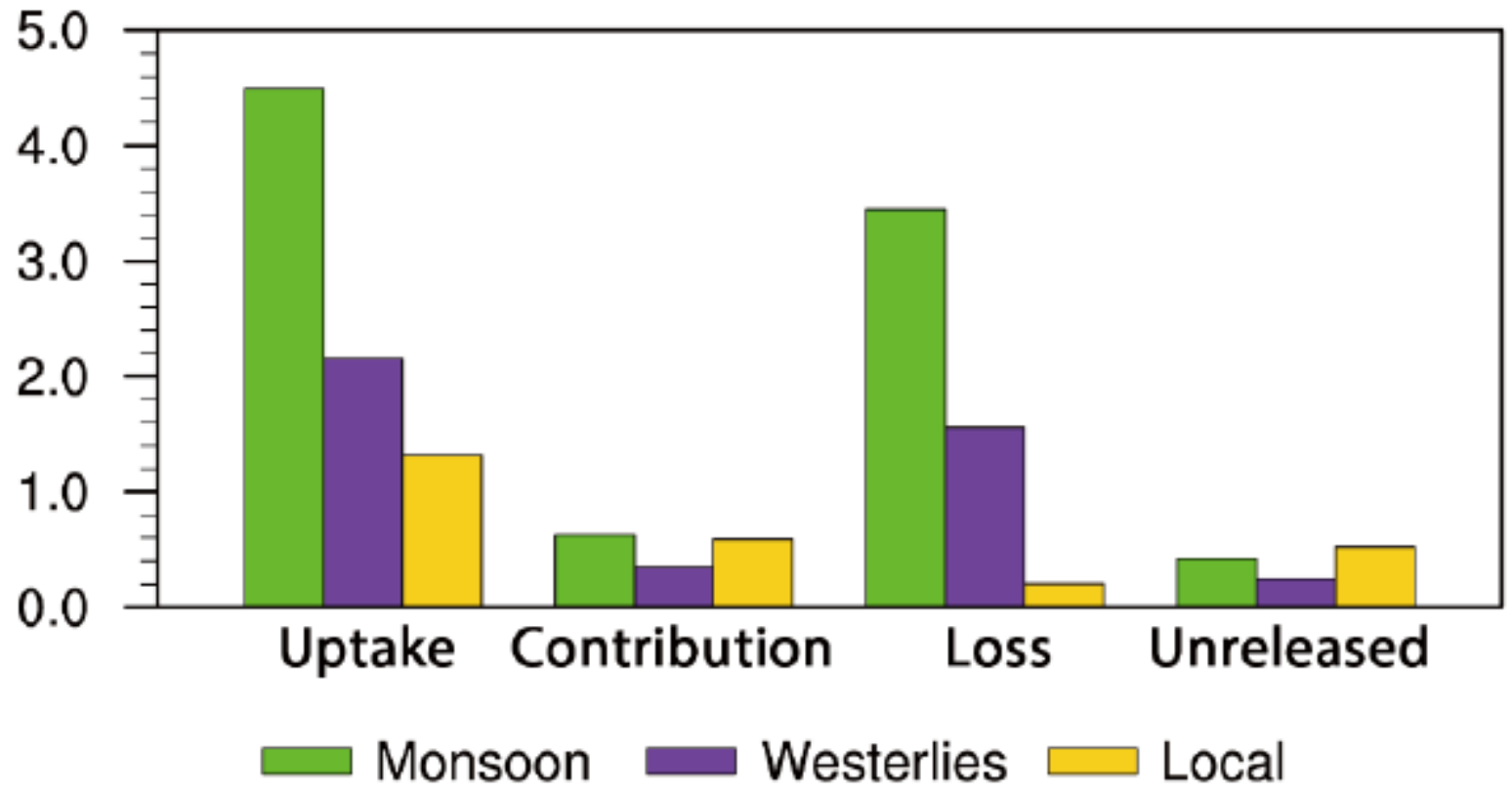


Figure 10

The differences in the average absolute contribution(units: 1014kg $\cdot y e a r-1)$ between the wet years and dry years (wet year - dry year) driven by summer monsoon, the mid-latitude westerly winds and local evaporation, as well as the total moisture uptaken, en-route loss and unreleased water vapor. 